\title{
Potential Role of Randomised Control Trial in the Implementation of Evidenced-Based Practice from the Perspective of Diagnostic Imaging
}

\author{
Antwi W. K., Kyei K. A., Opoku S. Y. \\ Department of Radiography, School of Biomedical and Allied Health Sciences, University of Ghana, Korle-Bu, Accra, Ghana
}

Email address:

wkantwi@chs.edu.gh (Antwi W. K.)

\section{To cite this article:}

Antwi W. K., Kyei K. A., Opoku S. Y. Potential Role of Randomised Control Trial in the Implementation of Evidenced-Based Practice from the Perspective of Diagnostic Imaging. Clinical Medicine Research. Special Issue Radiographic Practice Situation in a developing Country. Vol. 4, No. 3-1, 2015, pp. 5-9. doi: 10.11648/j.cmr.s.2015040301.12

\begin{abstract}
Evidence-based practice (EBP) in imaging as in any health profession is to provide quality health care based on clinical governance. This is to ensure that quality care is provided daily based on a credible research evidence. Randomized Control Trial (RCT) has been accepted as the best research design to provide credible evidence of an intervention for patient care and if well conducted. Therefore other research methods need to be developed to provide credible systematic reviews for a wider application. It is clear that this research design has prospects in imaging, however for now imaging guidelines and general consensus of experts will still be preferred as RCTs are gradually being developed in imaging.
\end{abstract}

Keywords: Evidenced-Based Pactice, RCT, Imaging, Patients manament

\section{Introduction}

Evidence-based practice (EBP) in imaging as in any health profession is to provide quality health care based on clinical governance [1]. This is to ensure that quality care is provided daily based on a credible research evidence $[1,2]$. EBP seeks to appraise and use scientific evidence in healthcare interventions [3]. Thus quality information will be available for both patients and healthcare practitioners to make vital decisions for the good management of the patient. This is important because patients also need valuable and relevant evidence to make decisions on their management [4]. This requires the application of research evidence as the basis of practice as against any decision not based on evidence [5].

Randomized Control Trial (RCT) has been accepted as the best research design to provide credible evidence of an intervention for patient care and if well conducted, it reduces factors that weaken other types of studies [6]. However, critics of EBP see RCT as imperious rather than a way of improving practice and providing patients and practitioners alike with alternative information to base one's decisions on patient management [7]. This paper explores RCTs as the basis for EBP and its position in diagnostic imaging. RCT is first described and its status in imaging looked at.

\section{What is RCT}

An RCT is a research methodology where the hypothesis of the research is first stated [6]. For example in using chest radiography to screen for lung cancer in an RCT, the hypothesis was; detection of lung cancer reduces mortality and is cost effective [8]. RCTs are based on the positivist approach and therefore it is a quantitative design and because two or more groups are usually compared in their outcomes after the study it is seen as a comparative research method [9]. There are two aspects of RCTs which are Explanatory and Pragmatic trials. Explanatory trials are more concerned with single outcome measure because it seeks to determine the efficacy of an intervention [9, 10]. In considering several outcome measures, pragmatic trail (trial?) is preferred $[9,10]$. For example in a pragmatic RCT study conducted by [11] on three types of contrast media for intravenous urography, the outcome expected was safety, tolerance and diagnostic efficacy of the three media. In dealing with RCTs, the problem that usually arises is the question of what outcomes to measure [10].

Several health related and economic outcomes can be measured in trials based on the type of investigation and the problem that it wants to solve [12]. Explanatory design is 
homogeneous in the selection of population and same intervention is provided for the sample selected to achieve 'clean' evaluation effectiveness and the repercussions of an intervention, recruits heterogeneous population and intervention applied can be varied among the selected sample $[9,10]$. Moreover, in pragmatic trails (trials?) subjects can drop out of the study or refuse to be on the group to which he or she has been assigned to and still be analysed (in a method called intention to treat) [9]. This is one reason why RCTs are strongly preferred research method according to him.

RCTs can be biased when especially, researchers, subjects or the assessors are aware of which group is given which intervention [9]. Therefore, in most studies of RCTs, all should be blinded that is, participants should not know which group or intervention they have been given [6]. This ensures that any identified effects are as a result of the given intervention [13] and also particularly necessary when response criteria is subjective as in pain reduction. Moreover, for an accurate unbiased outcome, allocation of subjects to groups and the intervention given are concealed from the researchers and assessors [6].

Randomization is the preferred method in RCTs to randomly allocate the participants to the various study groups using computer algorithms [6]. The reasons are that it minimizes bias and also statistical theory is based on the premise of random sampling [13]. Placebos are usually given to the control group in particular if the study intervention is therapeutic [14]. According to Moyad [15], these placebos can have significant effect on the outcome of the study in what is termed 'the placebo effect' and to avoid this effect is one reason why the experimental and control groups are compared in RCTs.

This comparison creates a distinction between the specific effects of the intervention from the non-specific effects of the placebo [14]. Also another important reason for having a control group is to determine the efficacy of the intervention [15]. If this is not considered, the biases that may develop will lead to what is termed systematic error which will affect either of the groups being studied and might destroy the design [16]. After all these requirements of an RCT are taken care of, the statistical and clinical significance of any differences in the outcomes between the groups are finally assessed [9].

\section{RCTs in Diagnostic Imaging}

The basic use of RCT is to evaluate the effectiveness of an intervention which has previously been a drug administration but has now been applied to diagnostic interventions including screening programmes and management strategies [6]. Screening is an intervention as any other intervention and can genuinely be evaluated using RCTs [17]. Evidence has shown that RCTs have provided the best method of determining effective interventions, hence its application in screening [18]. The reason for screening using imaging such as in breast cancer with mammography or lung cancer using computer tomography enables information gathering for the benefit of the individual tested and the community [19].
In screening for both lung and breast cancer, RCTs have been used as the research design to establish evidence whether these technologies are valuable in helping to reduce mortality or the development of the condition [20]. It was also established that RCTs was the widely accepted and most accurate and powerful research method for evaluating health technologies [21] which include imaging and therapeutic modalities in radiography. Also RCTs have been used to establish that early plain radiography of the lumbar spine as a tool in diagnosing low back pain is not indicated and as such imaging guidelines should be followed [22, 24].

These studies helped to clear the controversy surrounding the value of plain radiography of lumbar spine resulting from low back pain as against clinical observation. However, it was impossible to blind these patients because it is not a drug intervention. Using imaging guidelines will prevent unnecessary irradiation of patients with ionizing radiation. Also the cost effectiveness of an examination with an imaging modality is very important. RCT was used for example in magnetic resonance imaging to determine its cost effectiveness for knee examination as against arthroscopy in the National Health Service [23]. An RCT comparing clinical diagnosis (control) with a diagnostic protocol using ultrasound and Alvarado [25] Score (intervention group) is found to speed up diagnosis. The study showed that ultrasonography is the most accurate procedure that enables clinicians to perform an immediate diagnosis and early treatment of many cases of appendicitis [26].

However, despite these roles of RCT as an evidence-based practice tool in radiography, problems are encountered in imaging as with any other diagnostic test using RCT as a research design [27]. For example, in exposing a group of low back pain patients to $\mathrm{x}$-rays (intervention) and another group on observational studies only to find that the studies were not beneficial to the interventional group is against the rule of radiation protection [28]. Ethically subjecting patients to ionising radiation for the sake of research evidence is not right. This is because the risk of stochastic effects of ionizing radiation has no threshold. Moreover, no one would like to be subjected to any risk if that risk would not be beneficial. This makes it difficult in getting control groups a requirement in all studies using RCTs.

The two objectives of ethical consideration in clinical research are to promote socially valuable clinical studies and to protect research participants from exploitation [29]. Although there are other imaging modalities such as Magnetic resonance imaging and ultrasound, the nature of imaging has rendered it difficult to apply RCTs as the source of credible evidence for practice. This is because sound imaging practice has been based generally on the agreement of proffered experts in any area of the practice which so far has been good [30].

Because of the changes that are going on in health care management, EBP is now becoming the norm for managing patients [30]. However, before EBP from systematic reviews of RCTs is embraced in imaging, one should be certain that this rigorous approach is really superior to what preceded it 
(i.e. using imaging guidelines). As has been argued, if guidelines are used, it should be based on systematic review of all quality research on a particular subject or good quality RCTs [31]. Further to this, these guidelines should have audit review criteria developed from guidelines recommendations, criteria that can be used to assess performance against best practices [31].

It should be understood that for now, not all areas of imaging are suitable or susceptible to the rigorous approach of RCT [30]. That is why radiology to date has been practiced based on consensus approach [32]. Experts in the field of imaging have argued that basing practice on the power of a full and systematic review for every set of guideline would be just unachievable [30]. Also the studies in radiography with $\mathrm{RCTs}$, normally find it difficult to get the required number for acceptable generalisabilty an important aspect of RCTs [33]. Also blinding which helps to reduce biases is at times difficult and so one has to rely on a case control studies whose only difference with RCT is lack of random allocation to groups [27]. Moreover, inclusion and exclusion criteria have also been a challenge. Much as it is important in RCTs to determine the inclusion and exclusion criteria in therapeutic studies, the process for diagnostic test has not well been developed [27].

For example researchers could not ethically ask a group of subjects to smoke for lung cancer screening. The same RCT controversy also occurred in mammography screening for breast cancer as to which age group should be considered [34] all because of the dangers of the ionizing radiation involved and its effectiveness.

With the advent of evidence-based practice, health professionals are confronted with the task of finding which evidence to choose to answer a clinical problem. Much as it is important to find and use the best research design [31] it is also equally important to apply the right research method to answer a specific question. This is because various forms of clinical questions require evidence from different research designs to provide answers to the questions [35]. Systematic reviews have significance in both diagnostic and therapeutic radiography. Research infrastructure in radiography could be built using systematic reviews especially where researchers need a solution to a clinical question [36]. It also reveals areas where either enough studies have not been done or evidence available is controversial [36].

However, the emphasis of the effectiveness of a research methodology has been on a quantitative review from RCTs [31]. This led to the ranking of various research designs according to the authors in terms of its value in a hierarchical order to provide credible evidence that answers a research question. At the upper most level of this hierarchy is systematic review and meta-analysis from RCTs followed by RCTs [31, 37, 38, and 39]. The best evidence to influence decision then is the one on top of the levels of evidence [40]. Evidence from the lower level according to him should therefore be applied only when there is no RCT to provide a solution to the question. Also the reason for systematic reviews is that most of the reviews that have been completed so far are based on the effectiveness of an intervention from RCTs [41]. In advocating for evidence-based practice (EBP) based on a systematic review from RCTs or meta-analysis, the demand on health professionals is to identify the research findings that form the basis of decisions on patient management [42].

However, according to Mulrow [43], there are dangers involved in basing decisions only on single research evidence or reviews that are unsystematic. The argument in support of good systematic reviews as the highest level of evidence has been because findings based on multiple RCTs underpin its development [31].

What makes RCTs stronger for the development of systematic reviews has also been that a thorough search is done with the aim of finding more studies as much as possible both published and unpublished [42] to furnish health professionals with an ample evidence of the effectiveness of an intervention. This is important as stated by [44] because practice will be outmoded if it is not based on current best evidence and its effect on patients will be dangerous. EBP based on systematic reviews from RCTs should therefore be seen as a method of managing patients from the principle of evidence based medicine that is developed to provide solutions to questions about individual clinical interventions [44]. This requires a very large and healthy scientific base which is sufficient enough to evaluate the effectiveness of different types of interventions [45]. Systematic reviews from various RCTs provide this requirement as indicated from literature.

Despite all these finer points of RCTs it is not the solution to all research questions. For example in trying to identify a rare or adverse effects of interventions or evaluating the various ways or changes in the delivery of service cohort studies is the choice [46]. Moreover, qualitative methods are also vital in EBP because understanding the attitude and behavior of both the patient and the practitioner permits the application of evidence in the most effective way [47]. Also according to Summerskill, [47] and Savage \& Callery, [48], the naturalistic approach is the best design able to explain the experiences of an individual which is related to a particular event or situation. Additionally, placebos cannot be given in cases like childhood leukemia RCTs [49]. Moreover, it has been cited that a well conducted RCT is very expensive [50]. This is because, large numbers of participants are required to generalize findings and go show enough power of that particular intervention [3]. Although, the importance of applying research evidence in health care cannot be compromised however, cost effectiveness should also not be ignored in health care [51].

Moreover, prolonged follow up and the duration of recruitment contribute to the cost of running the project [52]. Also the claim that systematic reviews from RCTs are comprehensive has been challenged. There is evidence to prove that several systematic reviews do not include potential evidence from non English language trials [53]. The language restrictions led [53] to perform a meta-analysis on reported RCTs only to discover that $93 \%$ of these RCTs were 
excluded because the language was not in English. This situation is acceptable provided no English language RCTs are poorly reported [53].

\section{Conclusion}

In conclusion the various ways that RCTs have been applied in imaging has been discussed. It is clear that this research design has prospects in imaging, however for now imaging guidelines and general consensus of experts will still be preferred as RCTs are gradually being developed in imaging. Also several reasons such as radiation exposure make RCT application in imaging unethical in some areas. Beside that RCTs cannot solve all the problems faced in health care as one attempts to apply research evidence in patient management.

Therefore other research methods need to be developed to provide credible systematic reviews for a wider application. Moreover, non English language reviews should be critically examined so as to prevent potential evidence being discarded. However, RCT will continue to thrive as it has proved to be a gold standard in evaluating the effectiveness of health care interventions compared to other research designs.

\section{References}

[1] Behi RH. Encouraging evidence-based nursing. Evidence 1999; 4 : $1-8$

[2] Behi RH. Encouraging evidenced-based practice. Evidence 2000; 5: 1-4

[3] Hamer S. Evidence-based practice. In Hamer S and Collison G (eds) Achieving Evidence-based Practice. A handbook for practitioners, 1999. Edinburgh: Bailliere Tindall.

[4] Altman DG \& Bland JM. Treatment allocation in control trials: Why randomise? British Medical Journal 1999; 318 (7192):1209

[5] Ashcroft R, Hope T, Parker M. Ethical issues and evidencebased patient choice. In Edwards $G$ and Elwyn $G$ (eds) Evidence-based Patient Choice: Inevitable or impossible? 2001, Oxford: University Press.

[6] Humphris D. Types of evidence. In- Hamer S and Collison G (eds) Achieving Evidence-based Practice. A handbook for practitioners, 1999. Edinburgh: Bailliere Tindall.

[7] Gross R. Decisions and Evidence in Medical Practice: Applying evidence-based medicine to clinical decision making, 2001. St. Louis: Mosby.

[8] Webster P. Evidence-based practice - What is it and how can it be encouraged in orthopaedic nursing? Journal of Orthopaedic Nursing. 2002; 6(3): 140-143.

[9] Evans D. Hierarchy of evidence: a framework for ranking evidence evaluating health care interventions. Journal of Clinical Nursing 2003;12 (1): 77-84

[10] Jadad AR. Randomised Control Trials. A user's guide. BMJ Books, 1998. http:/www.bmjpg.com/rct/htlm.

[11] Roland M, Torgerson DJ. Understanding control trials. What are pragmatic trails? British Medical Journal, 1998a; 316 (7127): 285.

[12] Harding JR. Bertazolli M. Spinazzi A. A randomised, doubleblind, parallel group trial of iomeprol, iohexol and iopamidol in intravenous urography. British Journal of Radiology 1995; 68 (811): 712-715

[13] Roland M. Torgerson DJ. Understanding control trials. What outcomes should be measured? British medical Journal 1998b; 317 (7165): 107513.

[14] Day \&Altman. Blinding in clinical trials and other studies. British Medical Journal 2000; 321 (7259): 504.

[15] Moyad MA. The placebo effect and randomised trials: Analysis of alternative medicine. Urologic Clinics of North America 2002; 29 (1): 135-155.

[16] McGovern DPB. Randomised control trials. In-McGovern D.P.B., Summerskill W.S.M., Valori R.M et al (eds) Key Topics in Evidence-Based Medicine. 2001, Edinburgh: Padstow.

[17] Markham IS. Ethical and legal issues. British Medical Bulletin 1998; 54 (4): 1011-1021.

[18] Ellis JRC. Gleeson FV. Lung cancer screening. British Journal of Radiology 2001;74 (882): 478-485.

[19] Prescott RJ, Councell CE, Gillespie WJ et al. Factors that limit the quality, number and progress of randomised controlled trials. Health Technology Assessment 1999;3(20): 1-139

[20] Kendrick D, Fielding K, Bentley E et al. Radiography of the lumber spine in primary care patients with low back pain: Randomised control trial. British Medical Journal 2001; 322 (7283): 400-405.

[21] Max MB. Small clinical trials: In Gallin J (ed) Principles and Practice of Clinical Research. 2002, San Diago: Academic Press.

[22] Van den Bosch MAAJ., Hollingworth W, Kinmonth et al. Evidence against the use of lumber spine radiography for low back pain. Clinical Radiology 2004; 59 (1): 69-76

[23] Alvarado AA. Practical score for the early diagnosis of acute appendicitis. Annals of Emergency Medicine 1996;15: 557564.

[24] Kerry S., Hilton S., Patel S et al. (2000) Routine referral for radiography of the patients presenting with low back pain: is patients' outcome influenced by GPs' referral for plain radiography? Health Technology Assessment 4 (20): 1-119

[25] Knottnerus JA, Weel CV. General introduction of diagnostic procedures. In Knottnerus J.A (ed) The Evidence Base of Clinical Diagnosis. London: 2002, BMJ Books.

[26] Halpin SFS, Yeoman L, Dundas DD. Radiographic examination of the lumbar spine in a community hospital: an audit of current practice. British Medical Journal 1991; 303: 813-815

[27] Miller FG, Emanuel EJ, Rosenstein DL et al. Ethical issues concerning research in complementary and alternative medicine. Journal of the American Medical Association 2004; 291 (5): 599-604

[28] Bury B. How to synthesize evidence for imaging guidelines. Commentary. Clinical Radiology 2004; 59 (1): 62. 
[29] Lotus-Hills A, Mclnnes L, Richens Y. Evidence-based practice In Hinchliff S., Norman S and Schober J (eds) Nursing Practice and Health Care. 2003, London: Arnold.

[30] Matowe L, Gilbert FJ. How to synthesize evidence for imaging guidelines. Clinical Radiology 2004; 59 (1): 63-68.

[31] Black WC. Should this patient be screened for cancer? Effective Clinical Practice 1999; 2:86-95

[32] Wells J. Mammography and the politics of randomised control trials. British Medical Journal 1998; 317: 1224-1230.

[33] Sackett DL, Wennberg JE. Choosing the best design for each question. It's time to stop squabbling over the "best" methods. British Medical Journal 1997; 315: 1636.

[34] Brealey S, Glenny AM. A Framework for radiographers planning to undertake a systematic review. Radiography 1999; 5(3): 131-146.

[35] Trinder L, Reynolds S. Evidence-Based Practice: A critical appraisal. 2000, Oxford: Blackwell Science.

[36] Sackett DL, Rosenburg WC, Gray JA et al. Evidence based practice what it is and what it isn't. British Medical Journal 1996; 312 (7023): 71-72

[37] Barton S (2000) Which clinical studies provide the best evidence? British Medical Journal 321 (7256): 255-256

[38] Seers R. Systematic review. In Dawes M., Danies P., Gray A., Mant J., Seers K and Snowball R(eds) Evidenced-Based Practice: A primer for health care professionals. 1999. Edinburgh. Churchill Livingstone.

[39] French B. Developing the skills required for evidence-based practice. Nurse Education Today 1998;18(1): 46-51.

[40] Mulrow CD. Rational for systematic reviews. British Medical Journal 1994; 309: 597-599

[41] Sackett DL, Richardson W, Rosenburg W et al, Evidencebased Medicine: How to Practice and Teach EBM. 1997, London: Churchill Livingstone

[42] Kitson A. Using evidence to demonstrate the value of nursing. Nursing Standard 1997; 11 (16): 34-39
[43] Summerskill WSM. Qualitative research. In- McGovern D.P.B., Summerskill W.S.M., Valori R.M et al (eds) Key Topics in Evidence-Based Medicine. 2001, Edinburgh: Padstow.

[44] Savage E. Callery P. Parental participation in the care of hospitalised children: a review of the research evidence. In Glasper E.A and Ireland L (eds) Evidence-based Child Health Care. Challenges for practice. 2000, London: MacMillan Press.

[45] Kodish E, Eder M, Noll RB et al. Communication of randomisation in childhood leukemia trials. Journal of The American Medical Association 2004; 291(4): 470-475.

[46] Walker F and Sofaer B (2003) Randomised controlled Trial in the evaluation of non-biomedical therapeutic interventions for pain: The gold standard? NT Research 8 (5): 317-329.

[47] Hewitt-Taylor J. Evidence for Practice. Intensive and Critical Care Nursing 2003; 19 (2): 85-91.

[48] Moher D, Fortin P, Jadad AR et al. Completeness of reporting of trials published in languages other than English: Implications for conduct and reporting of systematic reviews. Lancet 1996; 347 (8998): 363-366.

[49] Gregoire G, Derderian F, Le Lorier J. Selecting the language of the puplications included in a meta-analysis: is there a tower Babel bias? Journal of Clinical Epidemiology 1995; 48 (1): $159-163$.

[50] Walker F and Sofaer B (2003) Randomised controlled Trial in the evaluation of non-biomedical therapeutic interventions for pain: The gold standard? NT Research 8 (5): 317-329.

[51] Hewitt-Taylor J. Evidence for Practice. Intensive and Critical Care Nursing 2003;19 (2): 85-91.

[52] Moher D, Fortin P, Jadad AR et al. Completeness of reporting of trials published in languages other than English: Implications for conduct and reporting of systematic reviews. Lancet 1996; 347 (8998): 363-366.

[53] Gregoire G, Derderian F, Le Lorier J. Selecting the language of the puplications included in a meta-analysis: is there a tower Babel bias? Journal of Clinical Epidemiology 1995; 48 (1): 159-163. 